\title{
Media Coverage, Public Interest, and Support in the 2016 Republican Invisible Primary
}

\author{
Kevin Reuning and Nick Dietrich
}

\begin{abstract}
Donald Trump's success in the 2016 presidential primary election prompted scrutiny for the role of news media in elections. Was Trump successful because news media publicized his campaign and crowded out coverage of other candidates? We examine the dynamic relationships between media coverage, public interest, and support for candidates in the time preceding the 2016 Republican presidential primary to determine (1) whether media coverage drives support for candidates at the polls and (2) whether this relationship was different for Trump than for other candidates. We find for all candidates that the quantity of media coverage had significant and long-lasting effects on public interest in that candidate. Most candidates do not perform better in the polls following increases in media coverage. Trump is an exception to this finding, receiving a modest polling bump following an increase in media coverage. These findings suggest that viability cues from news media contributed to Trump's success and can be influential in setting the stage in primary elections.
\end{abstract}

$\square$ onald Trump's success in the 2016 primary season sparked serious reflection on the role of news media in elections. Prominent political scientists and political journalists argued that Trump's success was due at least in part to an abundance of media coverage for his candidacy. ${ }^{.}$It was Trump's constant coverage in media, they argued, that was pushing his poll numbers up and crowding out rival candidates. We assess this argument, asking: does media coverage drive support in primary elections? And was the relationship between media coverage and support different for Trump than for other candidates?

We focus on the "invisible primary," the campaigning that occurs prior to any primary elections. This term originally referenced a time period before an election when candidates quietly jockeyed to win the support of elites. ${ }^{2}$

A list of permanent links to Supplementary Materials provided by the authors precedes the References section.

* Data replication sets are available in Harvard Dataverse at https://doi.org/10.7910/DVN/UGKVTJ

Kevin Reuning is Assistant Professor at Miami University (Kevin.Reuning@gmail.com). His reserach focuses on political parties, social movements, latent variable modeling, and social network analysis. Nick Dietrich is a Doctoral candidate at The Pennsylvania State University (Dietrich.

Nicholas@gmail.com). His research focuses on human rights and political methodology.
In modern elections, news media intently cover candidates long before voting begins, making the invisible primary far from invisible. Although the invisible primary might more aptly be referred to as simply the pre-nomination phase, it is more important than ever for building support due to its increased visibility. During this period candidates build interest in their campaign and work to build a base of volunteers and donors. The public must choose who to support among several candidates of the same party before any votes have taken place, making news media particularly important for influencing opinions during this process. ${ }^{3}$ Similarly, news media must choose which candidates to cover increasingly early in the pre-nomination phase, building news story lines for some candidates and excluding others. ${ }^{4}$ Success in the invisible primary translates into support once voting starts and confers real advantages on candidates. ${ }^{5}$

We focus on three key dynamic factors that are important for performance in the invisible primary: voter support, public interest, and media coverage. ${ }^{6}$ Voter support is the intention to vote for a particular candidate. Voter support is typically measured using public opinion polls asking: "If the 2016 presidential election were being held today and the candidates were as below, for whom would you vote?"' Public interest is the degree to which people want to access information about a particular candidate. Interest does not necessarily imply support; the public may want to learn about a candidate because the candidate is shocking or unusual. Unlike support, public interest is a reflection of the preferences of all consumers, not just voters. Media coverage is the extent to which 
a candidate is covered in news. "The media" is not a single entity, but is comprised of many different sources. While we cannot perfectly capture the state of national media coverage given the wide variety of potential news sources, we focus on media sources that are consumed by a broad audience in order to best reflect the coverage that reaches most Americans.

We find that media coverage is consistently important for driving public interest in candidates, demonstrating that news media are influential in setting the stage in primary elections. In contrast, we do not find a reliable relationship between media coverage of a candidate and support for that candidate. In fact, Donald Trump was the only candidate in 2016 that saw an increase in support following increased media coverage, suggesting that media coverage contributed to Trump's primary election success. We find that media coverage drove interest and (sometimes) support for candidates, but find little evidence of the opposite relationship, demonstrating that news media are influential in setting the stage in primary elections.

We also contribute to research on media and public opinion by employing new methods that account for the complex dynamics of campaigns. Evaluating the claim that media coverage drives support for candidates is difficult because voter support, public interest, and media coverage influence one another endogenously. Voters might become interested in a candidate after being exposed to news coverage. Journalists might cover a candidate more when support for that candidate increases. Interest may precede support as voters first seek information about a candidate before making a judgment about how to vote. We use models that explicitly account for endogenous processes to understand how media coverage, public interest, and support interacted to create winners and losers during the 2016 invisible primary.

\section{Election Media Coverage: Causes and Consequences}

In deciding how to allocate coverage, news media act as gatekeepers, deciding which candidates are covered and to what extent. ${ }^{8}$ This gatekeeping role forces news media to choose which candidates receive public exposure, publicizing some candidates and excluding others. ${ }^{9}$ This often leads to tiers of candidates: "the hopeless, the plausible, and the likely." ${ }^{10}$ Decisions about which candidate to cover can influence public opinion, especially in primary elections where voters must choose between several candidates in the same party.

Academic theories of election journalism have focused on the role of journalistic norms and market forces in deciding how news media allocate coverage. ${ }^{11}$ We argue, based on existing evidence, ${ }^{12}$ that both journalistic norms and market incentives influence media behavior. Journalistic norms emphasize objective reporting, electability, and viability, while market incentives drive producers of news to publish stories that will generate revenue. These competing incentives influence decisions about which candidates the press will cover and how much attention it will devote to each of them.

\section{Journalistic Norms in Election Coverage}

A key norm in election coverage is that journalists ought to be objective in their reporting. ${ }^{13}$ In the context of the invisible primary, this norm leads journalists to cover candidates based on objective assessments of electoral viability. In practice, public opinion polls are the most readily available metric in judging electability. ${ }^{14}$ Journalists view opinion polls as a relatively unbiased source of information on who is in the lead, who is in the middle of the pack, and who can be ignored. ${ }^{15}$ In addition, many polls are funded in part or entirely by news organizations, giving journalists easy access to polling data. In large fields of candidates, opinion polls provide regularly updated information to journalists about the state of the race and the relative standing of candidates.

Polling data also help news media transform elections, relatively slow moving phenomena, into daily news. Opinion polls are a mainstay of "horse-race" election framing, where attention is focused on who is winning and the strategies that candidates are using. ${ }^{16}$ The horse-race frame incorporates electability into an ongoing story that captures the dynamic aspect of the race (which candidates gain or lose support over time) and objective measures of viability (which candidates are best positioned to win elections).

\section{Market Incentives and Media Coverage}

News media do not exist independently of market forces, and a combination of cultural and economic changes has led to increasing influence of the market on news content. These market forces apply significant influence on the gatekeeping aspect of the media. ${ }^{17}$ In particular, journalists have to consider what news consumers are interested in reading about when deciding what to cover. These incentives create pressure to cover events that attract more attention from viewers and that produce revenue.

The horse-race frame is itself a reflection of market pressures; consumers are more likely to read stories written in the horse-race frame. ${ }^{18}$ In addition to influencing the style of coverage, market pressures also influence which events are covered in the first place. ${ }^{19} \mathrm{We}$ argue that business incentives can drive producers of news to cover candidates who are interesting to the audience even when they are not electorally viable. Conversely, electable candidates might be covered less because the readership does not find them interesting. For example, candidates who are "firsts" in some aspect are covered more intensely than they would be otherwise because they are interesting to audiences, ${ }^{20}$ and disproportionate coverage is often given to unusual candidates and events. ${ }^{21}$ 
The effects of market pressure have grown. Media companies face increasing competition and changes to federal regulation that have heighted the impact of market forces on the newsroom. ${ }^{22}$ At the same time, increasing data availability allows media to directly quantify interest in articles and use this information to tailor their coverage to attract larger audiences. ${ }^{23}$ News media can now perceive and respond to changes in viewership caused by discrepancies between what is covered and what the public finds interesting.

During the 2016 election, Donald Trump discussed market forces of journalism explicitly, often boasting that he boosted interest in the race. CNN reportedly made an additional $\$ 100$ million in revenue during the 2016 election cycle compared to a typical election year. Analysts and media executives have attributed this revenue to coverage of the Trump campaign. ${ }^{24}$

\section{Effects of Media on Voters}

In addition to reacting to events on the campaign trail, news media make choices about coverage that influence public opinion. Candidates rely on media coverage to gain publicity; ${ }^{25}$ candidates with little to no coverage are viewed by voters as being unlikely to win. ${ }^{26}$ Media coverage of candidates is a particularly important signal of viability in primary elections because voters cannot make decisions based on party identification alone. Voters must therefore rely on cues (such as media coverage) to know which candidates are viable.

A variety of explanations have been suggested for how media cues drive support. ${ }^{27}$ First, voters might be operating strategically, trying to identify which candidates are most likely to win the general election. Media coverage is a form of status conferral, ${ }^{28}$ so voters may interpret media coverage as an indicator of who is electable. ${ }^{29}$ Second, coverage can lead to a band-wagoning, where voters support the candidates who they believe other voters are supporting. ${ }^{30}$ Finally, there is a large literature within political psychology and political communication about the nature of public opinion as a reflection of what is most recently and easily accessible to voters. ${ }^{31}$

Beyond driving support for particular candidates, news media is an important force in setting the public agenda. ${ }^{32}$ Journalists shape the issue agenda by deciding how much coverage to allocate to individual issues, which in turn affects which issues the public is interested in. The same will be true for campaign coverage. As the press covers a candidate more, voters will be more interested in that candidate. ${ }^{33}$ Note that this is opposite but similar to the dynamic above where we discuss how the media responds to public interest.

News media's role may be of particular interest in the 2016 invisible primary. Political scientist John Sides argued during the invisible primary that Trump's polling surge was "almost certainly" due to frequent media coverage of his campaign. ${ }^{34}$ Sides unambiguously concludes that, "Trump is surging in the polls because the news media has consistently focused on him since he announced his candidacy on June 16." 35 Sides and Vavreck call these media-driven surges the "discovery phase" of a campaign. ${ }^{36}$ Political journalist Nate Silver similarly argues that "Trump's being in the media spotlight tends to help him in the polls, which in turn keeps him in the spotlight, which in turn helps in the polls, and so forth." 37 Nate Cohn, political journalist at the New York Times, states that "Donald Trump's surge in the polls has followed the classic pattern of a media-driven surge." ${ }^{\text {3 }}$ These authors cite Trump's shocking and unusual rhetoric as the reason for sustained media attention on his candidacy, including his criticism of Senator John McCain for being captured in the Vietnam $\mathrm{War}^{39}$ and his proposal to ban Muslims from immigrating to the United States. ${ }^{40}$

\section{Hypotheses}

The scholarship on election media outlined here suggests a series of endogenous relationships between media coverage, public interest, and support in polls. Figure 1 summarizes these relationships. When deciding whom to cover, news media will incorporate support in opinion polls and public interest. Hypotheses 1 and 2 outline these expectations.

HypothesIs 1: Increased support for a candidate in public opinion polls will increase media coverage of that candidate.

HypothesIS 2: Increased public interest in a candidate will increase media coverage of that candidate.

Voters will respond to these decisions by the media. First, media coverage will affect support for candidates in public opinion polls by signaling electoral viability and conferring status. This logic is captured in Hypothesis 3.

HypothesIS 3: Increased media coverage of a candidate will increase that candidate's support in public opinion polls.

Second, we expect that media coverage will affect public interest in candidates by increasing name recognition and building narratives that attract attention from viewers. ${ }^{41}$ This logic is captured in Hypothesis 4.

Hypothesis 4: Increased media coverage of a candidate will increase public interest in that candidate.

\section{Case Selection and Data}

We test our hypotheses using data from the 2016 Republican presidential primary. ${ }^{42} \mathrm{We}$ focus on this race because it was competitive, featured a large number of candidates, and is recent enough that data can be collected with necessary temporal precision. We analyze Jeb Bush, Ben Carson, Chris Christie, Ted Cruz, Carly Fiorina, 


\section{Figure 1 Endogenous relationships between media, interest, and support}

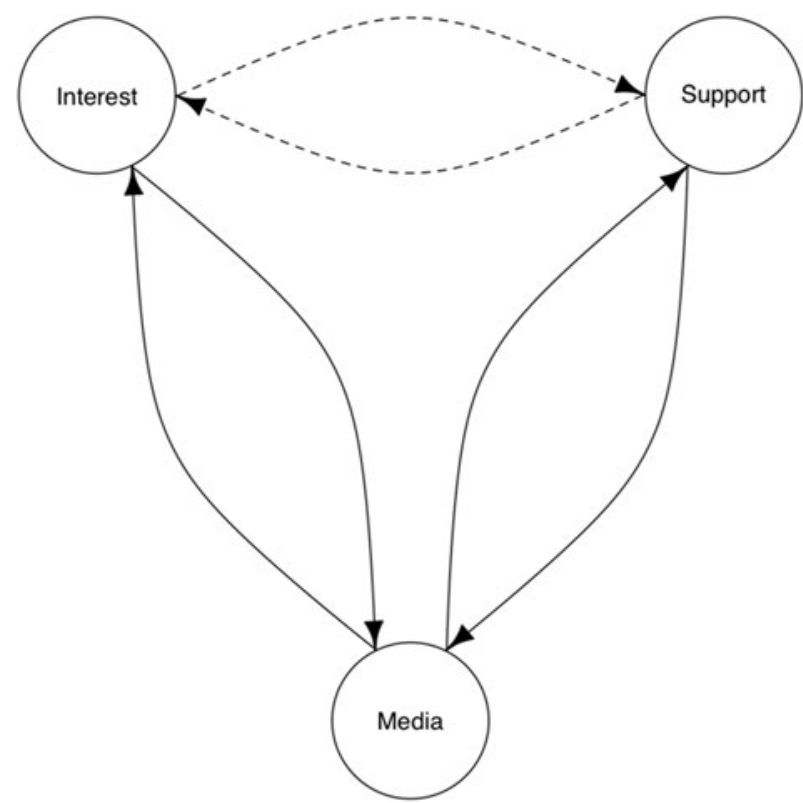

Note: Summary of relationships between three variables: media coverage, interest, and support. Directed arrows indicate causal relationships. The effect between interest and support is dashed because we do not have direct hypotheses about them but allow for a relationship in our modeling strategy.

Rand Paul, Marco Rubio, and Donald Trump. In addition, we collected data for Mike Huckabee and John Kasich but were unable to perform analyses on these candidates. There were instances during our time period where both received so few searches that Google did not make search statistics available for these two candidates. This surprised us, especially because John Kasich was the last candidate to drop out of the Republican Primary. The paradox of the Kasich campaign's longevity while it lacked public interest provides some evidence for the idea that Kasich's biggest supporters were the media. ${ }^{43}$

In order to test our hypotheses, we collected daily data on public interest, polling, and media coverage during the 2016 invisible primary. Daily information on each of our three series is necessary due to how quickly we expect them to influence one another. Aggregating to the weekly or monthly level would result in a loss of information about the relationship between the series.

There is no official start to the invisible primary. News media begin to report potential candidates before they even form campaign committees. The decision by polling firms to begin regular polling provides a reasonably good proxy for the beginning of the invisible primary. This, again, demonstrates how the term "invisible primary" may be a misnomer: we recognize that the invisible primary has begun when it becomes visible. For this study, our time frame for the 2016 invisible primary election ends the day before the Iowa Caucus (January 31, 2016) and begins when regular polling data becomes available (June 1, 2015).

\section{Voter Support}

We use voter support data collected by Huffington Post Pollster, ${ }^{44}$ which aims to include all national trial-heat polls that meet the minimal disclosure requirements set by the National Council on Public Polling. ${ }^{45}$ These polls vary in the firm conducting them, the sampling technique (internet, live phone, and automated phone) and the sampling frame (registered or likely voters) but they all asked who the voter would support in the primary election. ${ }^{46} \mathrm{We}$ include polls from May 1, 2015 to February 15, 2016-approximately 200 separate polls. ${ }^{47}$

There might be some concern with the use of polls to measure support for Donald Trump. Trump's surprise win in the 2016 general election has led to a debate over the reliability of polling. The most comprehensive assessment comes from the American Association for Public Opinion Researchers (AAPOR), who formed a committee of pollsters and academics to investigate the extent that polls underreported Trump's support. They found (in both the general and primary elections) that polling was roughly as accurate as it had been in previous cycles. In the general election state polls were not as accurate as previously but national polls were more accurate than in previous elections. Trump's surprise victory was less a result of polling and more a result of how journalists interpreted and explained election modeling. ${ }^{48}$

Because surveys are not fielded every day and there are overlapping windows when surveys are fielded, we combine data from multiple polls into a single daily measure of support. We calculate daily support in polls using a Loess line with a three-week span. ${ }^{4}$

\section{Public Interest}

Our measure of public interest is collected using Google search information for each candidate. ${ }^{50}$ Previous studies have found that online searches are a valid measure of public interest, correlating highly with related measures. ${ }^{51}$ Google searches are appropriate for estimating grassroots interest because they are gathered directly from individual user searches and capture an intention to access information about candidates.

Public interest is measured using the proportion of daily searches for the full name of each candidate by United States internet users. Google provides daily information about search volume in relative units for 90-day windows. We rescaled search volume such that it reflects the proportion of searches for a candidate among other candidates in the Republican primary. This is necessary because the raw number of searches for all 
candidates generally increases as the election draws closer. The true quantity of interest is not the total number of searches, but the proportion of searches relative to the other candidates. Individual values of our measure of public interest can be interpreted as the percentage of searches for a particular candidate among searches for all candidates of the same party on the same day.

\section{Media Coverage}

To gauge media coverage of each candidate, we scraped closed captions for major TV news networks (CNN, FOX News, and MSNBC) from the Internet Archive TV News Database ${ }^{52}$ for each day in our sample. Our script searched the TV News Caption Database for each candidate's full name and then counted the number of mentions of the candidate's last name in the returned text. ${ }^{53}$ We included the entire day's programing in our search. Once all candidate mentions were counted, we calculated the percentage of mentions for each candidate among total mentions of Republican candidates. These series can be interpreted as the total percentage of discussion of Republican candidates that focused on, for example, Jeb Bush, for each day in our time period.

Using television news to measures media coverage is advantageous for two reasons. First, television news has limited space, which necessitates decisions about what to cover and how much time to devote to each story. Second, our television news sources are distributed nationally. This allows us to capture news consumed by a broad audience. In contrast, newspapers and online media have highly fragmented audiences, making representative measures of coverage for these sources difficult to achieve. "Media coverage" is difficult to measure because individuals are exposed to different coverage depending on which sources they access. We chose television news that is broadcast nationally because it most closely approximates the coverage that a typical American consumes.

Figure 2 displays daily media coverage, public interest, and support for Donald Trump and Ted Cruz in the 2016 election between June 1, 2015 and January 31, 2016. Donald Trump dominates media coverage for most of this time period while gaining a plurality (but not a majority) of support. Near the end of our time period Ted Cruz gains media coverage, public interest, and support.

\section{Modeling Endogenous Relationships}

As discussed earlier, we posit an endogenous relationship with complicated dynamics. We model this system of equations using Bayesian Structural Vector Autoregression. We use this method because it explicitly models endogenous, autoregressive processes, and does not suffer many of the limitations of traditional vector autoregression. All models require assumptions, and this is especially true for time series models. The advantage of Bayesian Structural Vector Autoregression is that it provides a better avenue for quantifying and testing these assumptions.

Briefly, Bayesian Structural Vector Autoregression (BSVAR) is an extension to vector autoregression. Like vector autoregression, BSVAR models the relationship between multiple time series with endogenous relationships. Each series (voter support, public interest, and media coverage) is both a dependent and an independent variable. Unlike traditional vector autoregression, BSVAR does not require pre-tests or strong assumptions about stationarity. While BSVAR still requires assumptions about causal ordering, we can test the effects of these assumptions. ${ }^{55}$ We provide a detailed discussion of Bayesian Structural Vector Autoregression, the details of our model specification, and the robustness of our findings to alternative specifications in the online appendix. We fit a separate model for each candidate in the sample. ${ }^{56}$

In addition to the three primary variables of interest, we included the primary debates as exogenous variables. Each debate is represented by a binary variable equal to 1 for the day of the debate and 0 for all other days. There were a total of 7 debates in our time frame for the 2016 Republican primary. The debate variables capture sudden changes caused by the debates. Including exogenous debate indicators is necessary because political debates can cause sudden fluctuations in public interest which could otherwise be misattributed to media coverage (or vice versa).

\section{Results}

We test our expectations about media, interest, and polling by examining Impulse Response Functions (IRFs). IRFs show how an increase (or shock) to one series affects another series over time. ${ }^{57}$ This allows us to see how changes in one series affect another series in the time after the increase in the original series. We normalized the shocks such that they show the effect of a one percentage point change to each variable. This normalization makes it easier to compare the substantive size of effects across candidates and across variables. For example, an IRF showing the effect of media coverage on support can be interpreted as showing the expected change in the percentage of people reporting support for a candidate in polls following a one-point increase in the percentage of media coverage devoted to that candidate. The following plots show the expected change during a five-day window after the initial shock. In examining most of the series, we believe that this time window shows the general tendency of the relationship. Predictions beyond this five-day window are less informative because our predictions become less certain the further we forecast from the initial shock. We estimate $95 \%$ credible intervals around the change using the eigendecomposition of the likelihood as detailed in Sims and Zha. ${ }^{58}$ 
Figure 2

Media, interest, and support for Trump and Cruz in 2016 primary
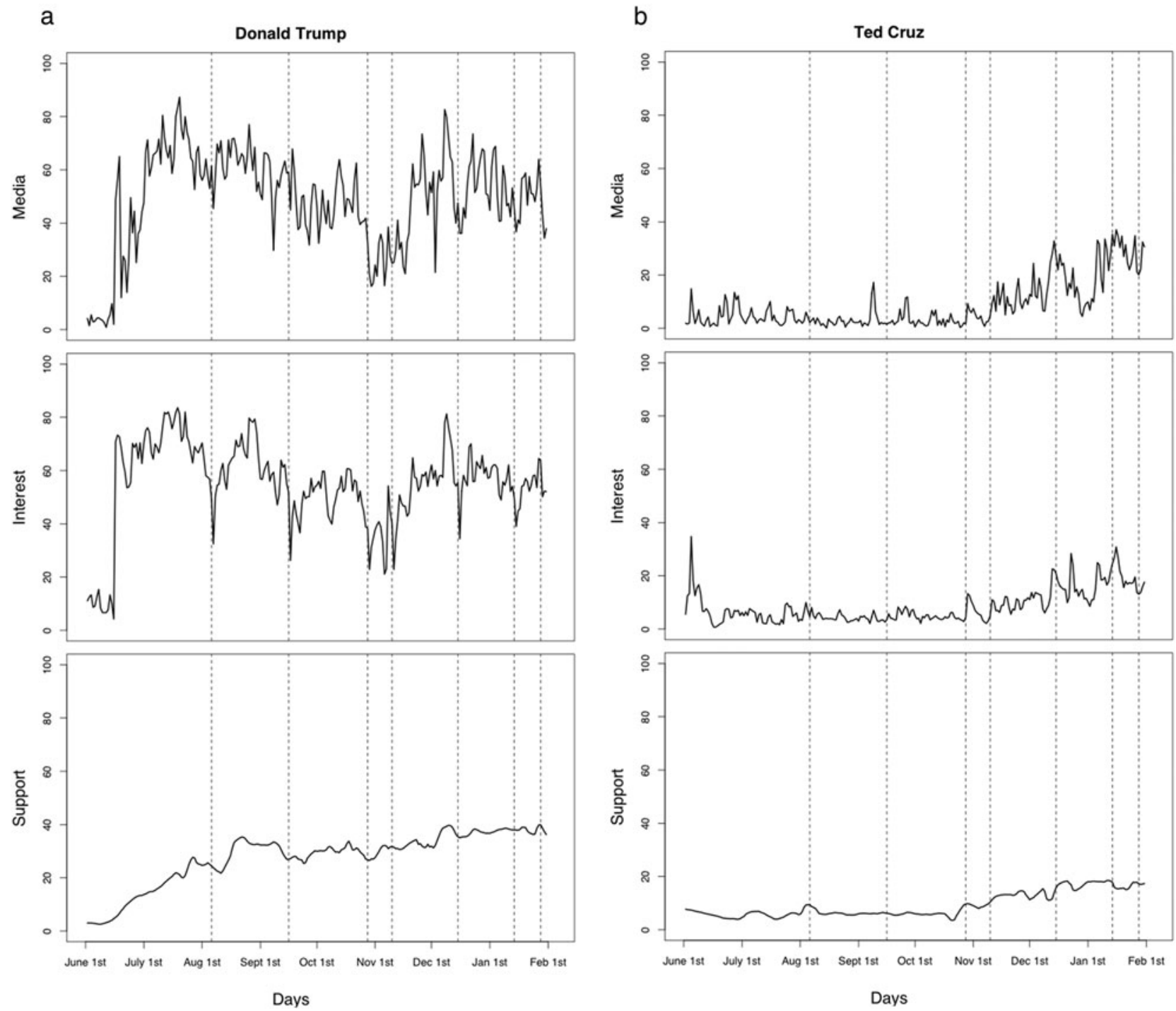

Note: Media coverage, public interest, and polling for Donald Trump and Ted Cruz. The dashed lines indicate primary debates. Refer to the text for details on each measure.

\section{Donald Trump}

Because Donald Trump's campaign drew intense media attention and scrutiny of the role of media in elections, we start by examining media coverage, public interest, and support in polls for the Trump campaign. Figure 3 plots the 9 IRFs of the relationships between these three series for Trump. The left most column shows what happens when there is a one percentage point increase to media coverage, the middle column a one percentage point increase to interest, and the right most column a one percentage point increase to support for Donald Trump. Each row shows the effect of the one percentage point increase to different variables with the top row showing the effect on media, the middle row the effect on interest, and the bottom row the effect on polling. The diagonal shows the effect of the series on itself, demonstrating how persistent these increases are. We find that increases in all three series lead to future growth, suggesting that all three factors of interest are autoregressive. The off-diagonal plots show the relationships across variables.

Starting in the left column, we test our expectations about the effects of media. In Hypothesis 3 we expected that an increase in media coverage would lead to an increase in support for a candidate, while in Hypothesis 4 we expected media coverage to drive public interest. We 


\section{Figure 3}

Impulse response functions for Trump
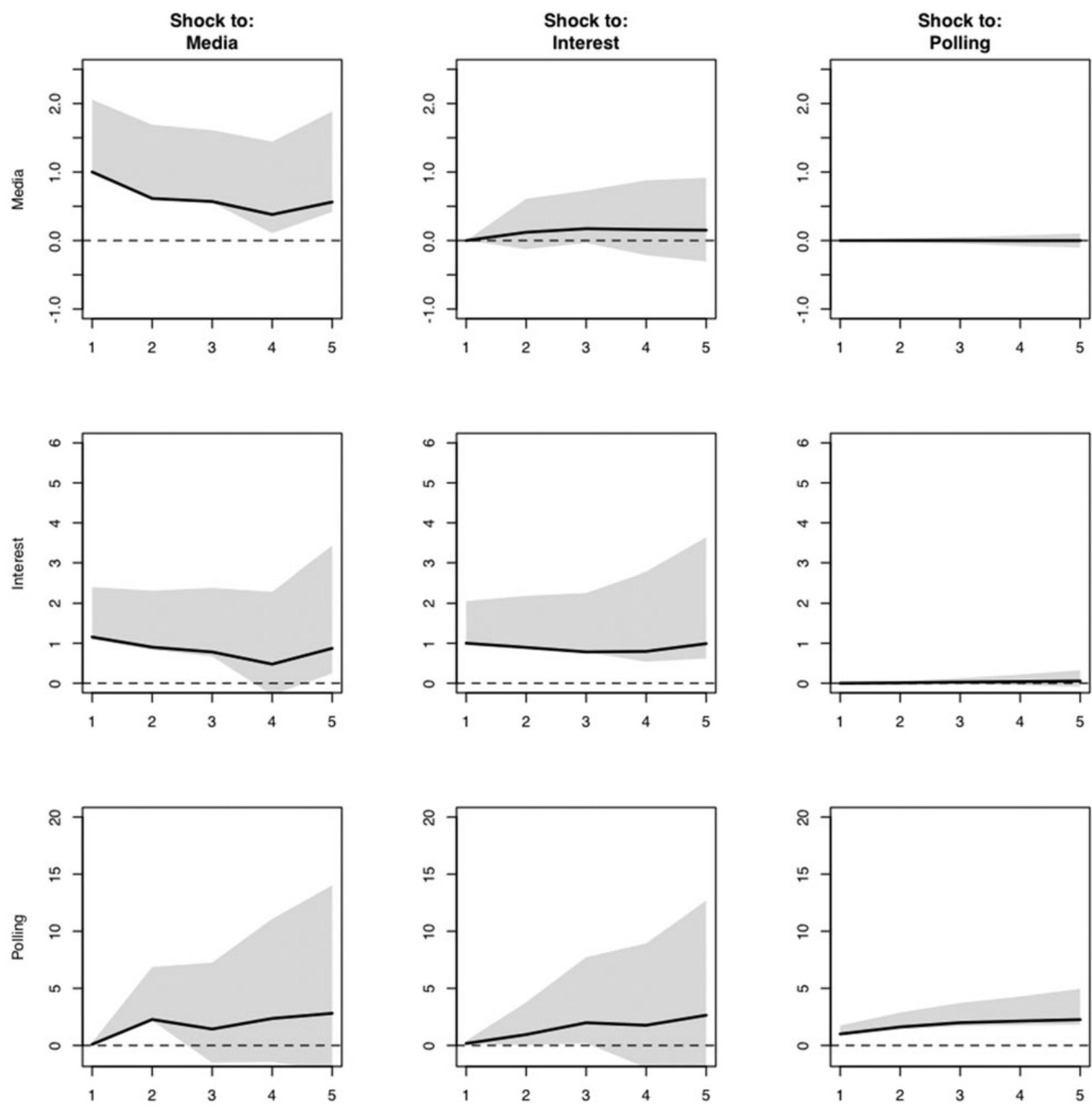

Note: Impulse Response Functions for the relationships between media coverage of, support of, and interest in the candidacy of Donald Trump. IRFs were normalized to show the effects of a 1 point increase in one of the three variables across 5 days.

find clear evidence of Hypothesis 4, and somewhat mixed evidence of Hypothesis 3. Trump experienced significant increases in public interest for three days following a one percentage point increase in media coverage. He also experienced a shorter-term bump in support in polls following an increase in media coverage.

Meanwhile, we find little evidence for Hypotheses 1 or 2. Media coverage of Trump did not change significantly following bumps in public interest or support in polls.

These results lend some support to the claim that Trump's rise was media-driven. Spikes in coverage significantly drove interest and support, while media did not significantly change the amount of coverage dedicated to Trump based on his levels of support or public interest based on our analysis. 

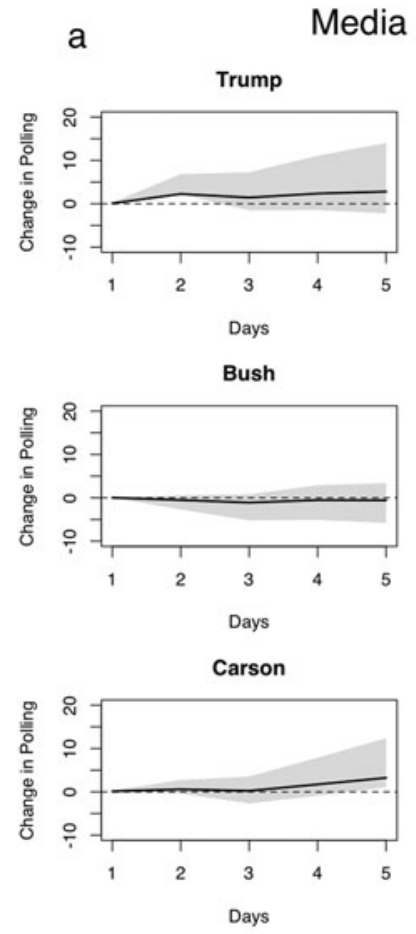

Christie

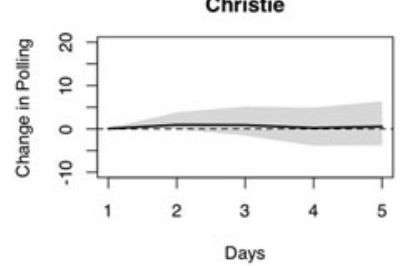

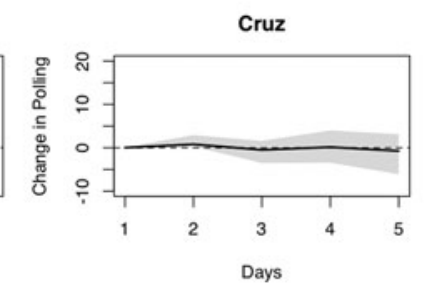
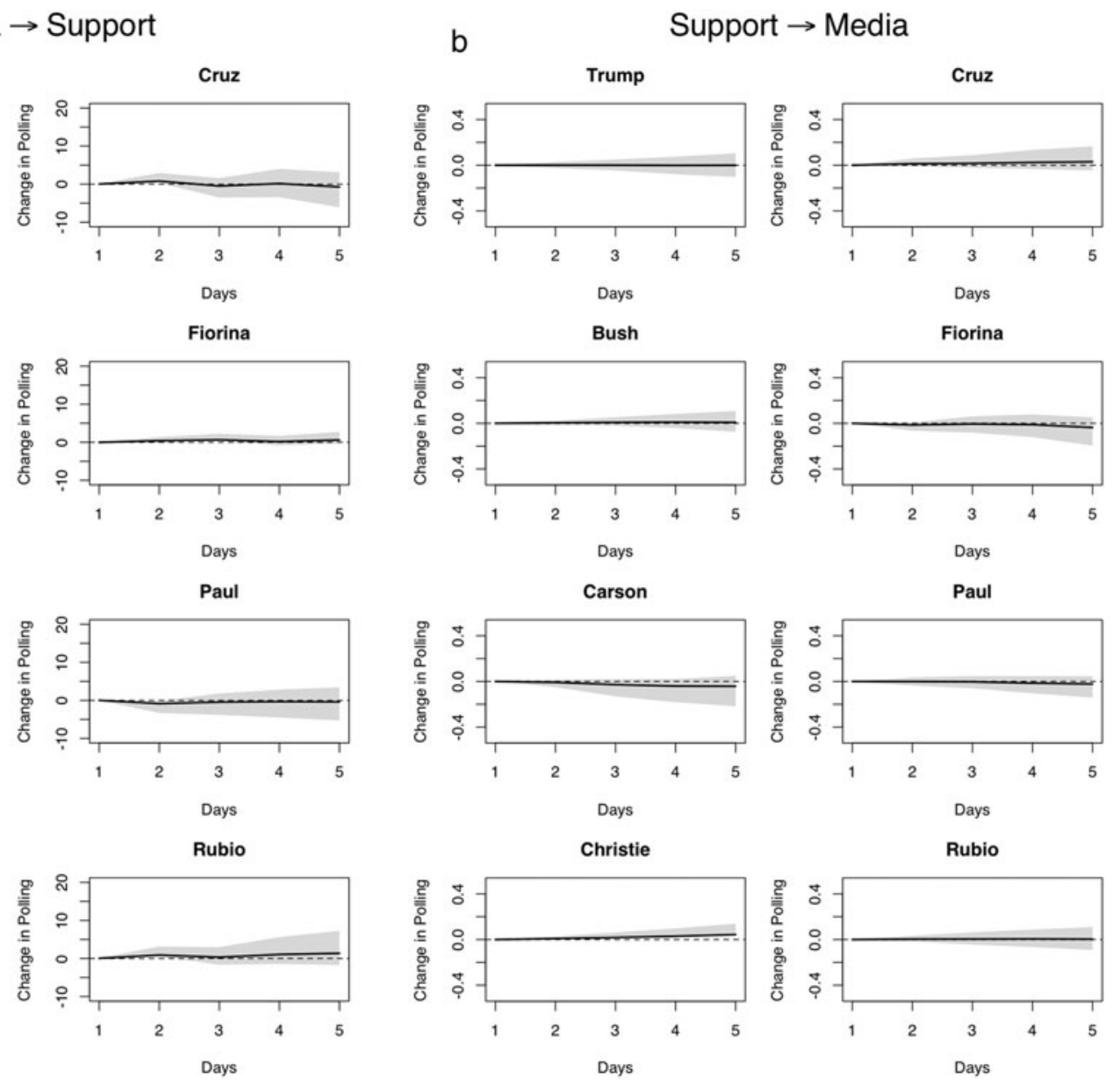

Note: IRFs showing the causes of changes in support for all major Republican primary candidates in the 2016 election. Gray area shows a $95 \%$ credible intervals.

\section{Other 2016 Candidates}

We now step back and examine relationships between media coverage, public interest, and support in polls across all candidates in the 2016 primary. Figure 4 displays the relationship between media coverage and support in polls for each candidate in our sample. Figure 5 displays the relationship between media coverage and public interest for each candidate in our sample.

Among the full sample of candidates, we find little support for Hypothesis 3, which states that media coverage will lead to increases in support. In fact, Trump is the only candidate who experienced significant increases in support after a bump in media coverage. This suggests that media coverage was a particularly crucial signal of viability for Trump as compared to other candidates. We speculate further about this relationship in the following section.

We also do not find support for Hypothesis 1, which states that higher support for a candidate in public opinion polls will lead to more coverage of that candidate. No candidate in the 2016 invisible primary experiences a significant bump in coverage following an increase in support. This suggests that media coverage is not changing in response to changes in candidate viability as reported by election polls.

Among the full sample of candidates, we find little support for Hypothesis 2, which states that increased public interest in a candidate will lead to increased media coverage of that candidate. We do, however, find strong support for Hypothesis 4, which states that media coverage will lead to increased public interest. Increased media coverage leads to consistently significant and long-lasting bumps in public interest. We find evidence of this relationship for every candidate in our analysis. This finding suggests that media coverage is highly important for name recognition and public familiarity with candidates.

Taken together, our results suggest that media coverage drives changes in public interest and support more than it 


\section{Figure 5}

Relationship between media and interest
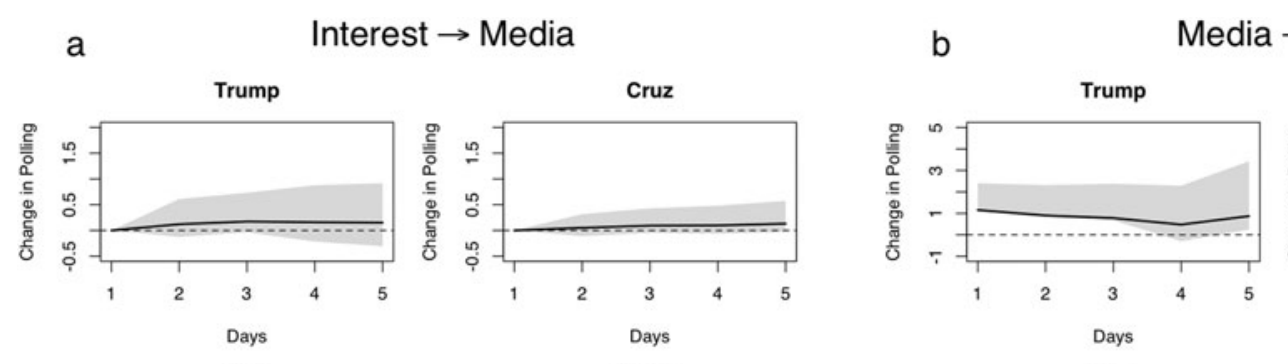

$\rightarrow$ Interest
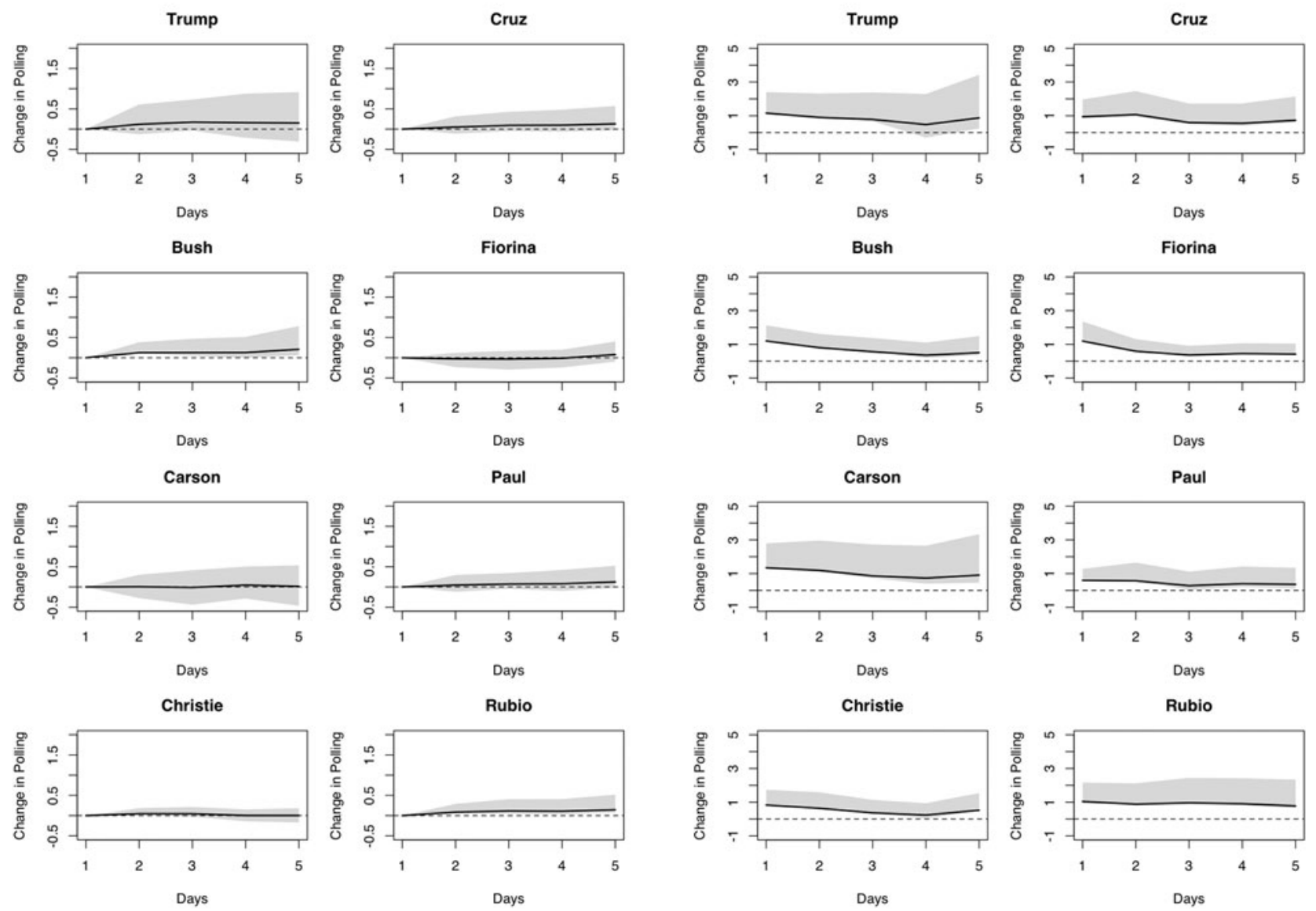

Note: IRFs showing the relationships between media and interest for all major Republican primary candidates in the 2016 election. Gray area shows a $95 \%$ credible intervals.

responds to them. Media coverage spikes lead to large jumps in public interest in candidates across the board. Evidence that media coverage drives support in polls is mixed, but a relationship was present at least for Trump, the eventual nominee. Meanwhile, the lack of significant effects of changes in support or public interest on media coverage suggests that news media are driving - and not simply reacting to-changes in the race.

\section{Conclusion}

We analyze the complex relationships among media coverage, public interest, and support in opinion polls for candidates in the 2016 Republican presidential primary. Our results suggest that media coverage is a driver of public interest in the invisible primary. Media coverage consistently leads to large and long-lasting increases in public interest for all candidates in our sample, demonstrating that media coverage is highly influential in setting the stage for primary elections. Meanwhile, bumps in media coverage resulted in an increase in support for Trump, but not for other candidates.

Why does Trump benefit disproportionately from media coverage? We offer a few speculative answers to this question. First, Trump dominated media coverage for much of our time period. It is hard to overstate the degree of media coverage Trump received; by February of 2016 he had already received nearly $\$ 2$ billion in free media, more than double any other candidate. ${ }^{59}$ Patterson notes that Trump received an unusual amount of coverage, often positive in tone, because journalists are "attracted to the new, the unusual, the sensational-the type of story material that will catch and hold an audience's attention." This level of media saturation may have signaled viability to voters and pushed Trump ahead of other candidates because his early levels of support as compared to media coverage were so far out of equilibrium. 
Second, Trump pushed policies that were out of step with many of the traditional Republican party positions held by other candidates. He may have particularly benefited from media coverage boosting his exposure because his policies stood out in a crowded primary field. One avenue for future research is investigating how news media's ability to affect the race changes with the number of candidates. In either case, Trump's coverage in news media seems to have preceded his support. Coverage of the Trump campaign was likely driven by his bombastic rhetoric, celebrity status, and policy proposals that were both radical and unusual.

Disproportionate coverage of Trump seems to have had a real impact on the 2016 invisible primary. This is cause for reflection about how news media determine what is newsworthy. Given our finding that media coverage drove public interest and support for Trump, it appears that running an unusual campaign can give candidates an advantage in the crowded invisible primary election field. This is an undesirable trait of the invisible primary that could encourage future radical candidates.

These are not minor concerns. The pre-nomination phase is what determines candidate standing going into the primary election, and ultimately determines which candidates are on the ballot in the general election. In the contest analyzed here, Trump ended the invisible primary with a plurality of support and successfully secured the nomination. While no nomination is made until voting has concluded, the landscape of the race is set before any ballots are cast. A candidate with high support when voting begins is well positioned to win the nomination.

Yet we do want to caution against overreaching. Donald Trump was the only candidate we analyzed whose support rose significantly with increased media coverage. At the same time, he was an atypical candidate. Trump held no previous elected office, but did have a large media presence and had previously made overtures to run for president. This gave him a powerful platform to start his campaign. It is unlikely that a candidate without such name recognition and profile would have been able to draw as much media attention so early in the race. Trump's continued monopoly over free media coverage in the general election is further testament to his anomalous campaign. ${ }^{61}$ Whether another candidate could repeat Trump's success by leveraging free media coverage remains to be seen.

A more general implication of our analysis is that public interest in candidates is consistently driven by media storylines. This leaves quite a bit of room for future research into how news media decide which candidates to cover. We did not investigate the effect of many potential indicators of viability, such as fundraising, elite endorsements, or scandals. We also leave open whether the tone of coverage matters, although our results seem to suggest that the volume of media coverage alone is enough to signal viability. Finally, we investigated only the 2016 primary field; other contests could behave differently. The invisible primary determines which candidates are selected into the general election and ultimately elected. The 2016 election should serve as a reminder of the need for better research on the dynamics of public opinion in the invisible primary season.

\section{Notes}

1 Cohn 2015; Sides 2015; Silver 2015.

2 Hadley 1976.

3 Once voting has begun, news media still play an important role in publicizing candidates, but largely do so on the basis of who has won previous state primary election contests. See Bartels 1988; Farnsworth and Litchter 2010; and Sides and Vavreck 2013 for a broader discussion of the news media in primary and general elections.

4 Belt, Just, and Crigler 2012.

5 Steger 2000; Adkins and Dowdle 2005; Norrander 2006; Cohen et al. 2008; Aldrich 2009; Steger 2013.

6 Readers may object that other factors, such as fundraising, elite endorsements, or scandals also affect the dynamics of the invisible primary. In the interest of brevity, we focus on the relationships between media coverage, public interest, and support in polls. However, we look forward to future work examining the effects of these and other factors.

7 This example is from an Ipsos/Reuters poll reported in The Huffington Post 2016. Exact question wording varies by survey.

8 Shoemaker and Vos 2009.

9 Belt, Just, and Crigler 2012.

10 Robinson and Sheehan 1983, 73.

11 These theories of journalism in democratic societies are formally referred to the as the "trustee model" of journalism and the "market model" of journalism, respectively, see Baker 2002.

12 Welbers et al. 2016.

13 Hackett 1984; Muñoz-Torres 2012; Bennett 2016.

14 Other metrics, such as campaign donations and elite endorsements, are likely also used to determine electoral viability. We restrict the scope of our analysis to the interactions between public opinion and media coverage, in part because these elite indicators of viability are inconsistently available. We look forward to future research on other signals of candidate viability.

15 Patterson 2005.

16 Benoit, Stein, and Hansen 2005; Broh 1980; Patterson 1980; Arterton 1984; Ansolabehere, Behr, and Iyengar 1991; Bartels 1988.

17 Bennett 2016; Patterson 2013; Hamilton 2004; McManus 1994. 
18 Iyengar, Norpoth, and Hahn 2004.

19 Tandoc Jr 2014.

20 Han 2011.

21 Haynes 2008; Skewes and Plaisance 2005.

22 Patterson 2013

23 Anderson 2012; Lee, Lewis, and Powers 2014.

24 Borchers 2016.

25 Sides and Vavreck 2013; Bartels 1988.

26 Abramowitz 1989; Irwin 2002; Dowdle, Adkins, and Steger 2009.

27 Sides and Vavreck 2013.

28 Lazarsfeld and Merton 1948.

29 Abramowitz 1989; Irwin 2002; Dowdle, Adkins, and Steger 2009.

30 Rothschild and Malhotra 2014.

31 Zaller 1992; Duckman and Lupia 2000; Chong and Druckman 2007; Leeper and Slothuus 2014.

32 Graber and Smith 2005; Soroka 2003; Tan and Weaver 2007; Van Aelst and Walgrave 2011; McCombs 2013.

33 Belt, Just, and Crigler 2012.

34 Sides 2015.

35 Ibid.

36 Sides and Vavreck 2013, 43-44.

37 Silver 2015.

38 Cohn 2015.

39 Ibid.

40 Silver 2015.

41 We note that there is likely a direct relationship between interest and support, but do not state any particular expectations about the direction or magnitude of this relationship. When modeling the relationships between interest, support, and media coverage we allow for media interest and support to directly affect each other. This relationship is outside the scope of the current study.

42 Although it is possible to perform the same analysis in the 2016 Democratic presidential primary, the small number of feasible candidates presents challenges for valid inference. The 2016 Democratic presidential primary featured only two major candidates for most of the time period of the invisible primary, meaning that an increase in one candidate's coverage must necessarily involve a corresponding decrease in the other candidate's coverage.

43 Libit 2015.

44 We compared Huffington Post Pollster to polls aggregated by Real Clear Politics. Differences between the two sources are minimal.

45 Huffington Post 2016.

46 There is some variation in how this question is asked, most firms used a traditional trial-heat question: 'If the election were held today ...'

47 Note that this differs slightly from the temporal domain of our analysis because we include relevant polls released before/after the time period in our moving average.

48 Kennedy et al. 2018.

49 The use of the Loess Line with a three week span means that daily support is estimated using only polls from a week and a half before and after the day being estimated. Each poll in this window is weighted based on time, using a tricubic function that downweights polls further from the day being estimated, and sample size, emphasizing polls with larger numbers of respondents. Polls are assigned to a single day using the median day the survey was in the field. The use of a Loess line and the requirement to assign each poll to a single day has the potential to create some bias in our estimates. In particular, it is possible that any estimated effect of polling might be a result of the measure being "artificially lagged." As a robustness check, we performed a second analysis where polls were measured using the first day in the field instead of the median date. The results are not substantially changed, and are available in the online appendix.

50 Google 2016.

51 Ripberger 2011; Zhu et al. 2012.

52 Internet Archive 2015.

53 We chose this approach because some candidates (such as Jeb Bush) had common last names which would potentially add random noise when only searching by last name. Other candidates (such as... Jeb Bush) share a last name with another political figure. Although this method has the potential to overrepresent candidates whose last names are used more often, this does not bias our results because our analysis focuses on the dynamics of each individual candidate's coverage over time. As long as there are no systematic changes in whether a candidate is referred to by first or last name, our measure captures the temporal variation in media coverage accurately.

54 While we acknowledge that our measure may not capture incentives specific to newspapers and online media, we believe that television news coverage is the most valid measure of media attention for this study due to its limited space and broad audience. Without individual-level data we are unable to investigate the effects of different news sources, especially highly individualized news exposure via social media. See Francia 2017 for a discussion of how Twitter contributed to coverage of Trump in the general election. Future research should consider how to investigate the effects of fragmented media sources on public opinion, especially as news is increasingly shared on social media. The measure employed here is indicative of the general amount of attention that candidates receive in news coverage.

55 Brandt and Freeman 2006. 
56 By estimating each candidate separately, we (1) avoid restrictive assumptions that effects must be identical between candidates, (2) prevent any one candidate from driving the results, and (3) avoid having to reparameterize to accommodate the fact that our series sum to unity across candidates. Fitting separate models allows media coverage of one candidate to have direct effects on public interest and polling for that candidate, but not other candidates. For example, increased media coverage of Ted Cruz can result in a polling bump for Ted Cruz, but cannot affect polls for Marco Rubio. Note that candidates can still have indirect effects on one another by drawing interest/support/coverage away from other candidates.

57 Brandt and Freeman 2006; Sims and Zha 1999.

58 These error bands do not impose assumptions about normality and account for temporal correlation; see Brandt and Freeman 2006. We calculate uncertainty using the first component of the eigendecomposition, which accounts for the majority of variation in our cases; see Sims and Zha 1999 for more information.

59 Confessore and Yourish 2016.

60 Patterson 2016.

61 Francia 2017.

\section{Supplementary Materials}

Outline of Appendix

Bayesian Structural Vector Autoregression BSVAR

Robustness to Priors

Robustness to Identification

Robustness to Polling Aggregation

To view supplementary material for this article, please visit https://doi.org/10.1017/S1537592718003274

\section{References}

Abramowitz, Alan I. 1989. "Viability, Electability, and Candidate Choice in a Presidential Primary Election: A Test of Competing Models." Journal of Politics 51(4): 977-92.

Adkins, Randall E. and Andrew J. Dowdle. 2005. "Do Early Birds Get the Worm? Improving Timeliness of Presidential Nomination Forecasts." Presidential Studies Quarterly 35(4): 646-60.

Aldrich, John. 2009. "The Invisible Primary and Its Effects on Democratic Change." PS: Political Science and Politics 42(1): 33-39.

Anderson, C. W. 2012. "Between Creative and Quantified Audiences: Web Metrics and Changing Patterns of Newswork in Local US Newsrooms." Journalism 12(5): 550-66.

Ansolabehere, Stephen, Roy Behr, and Shanto Iyengar. 1991. "Mass Media and Elections: An Overview." American Politics Quarterly 19(1): 109-39.
Arterton, F. Christopher. 1984. Media Politics: The News Strategies of Presidential Campaigns. Lanham, MD: Lexington Books.

Baker, Edwin C. 2002. Media, Markets, and Democracy. New York: Cambridge University Press.

Bartels, Larry M. 1988. Presidential Primaries and the Dynamics of Public Choice. Princeton, NJ: Princeton University Press.

Belt, Todd L., Marion R. Just, and Ann N. Crigler. 2012. "The 2008 Media Primary: Handicapping the Candidates in Newspapers, on TV, Cable, and the Internet." International Journal of Press/Politics 17(3): 341-69.

Bennett, W. Lance. 2016. News: The Politics of Illusion. Chicago: University of Chicago Press.

Benoit, William L., Kevin A. Stein, and Glenn J. Hansen. 2005. "New York Times Coverage of Presidential Campaigns." Journalism \& Mass Communication Quarterly 82(2): 356-76.

Borchers, Callum. 2016. "Yes, Donald Trump Has Been Good for the Media Business." Washington Post, October 25.

Brandt, Patrick T. and John R. Freeman. 2006. "Advances in Bayesian Time Series Modeling and the Study of Politics: Theory Testing, Forecasting, and Policy Analysis." Political Analysis 14(1): 1-36.

Broh, C. Anthony. 1980. "Horse-Race Journalism: Reporting the Polls in the 1976 Presidential Election." Public Opinion Quarterly 44(4): 514-29.

Chong, Dennis and James N. Druckman. 2007. "Framing Theory" Annual Review of Political Science 10: 103-26.

Cohen, Marty, David Karol, Hans Noel, and John Zaller. 2008. The Party Decides. Chicago: University of Chicago Press.

Cohn, Nate. 2015. "The Trump Campaign's Turning Point." New York Times, July 21. Available at https:// www.nytimes.com/2015/07/21/upshot/the-trumpcampaigns-turning-point.html.

Confessore, Nicholas and Karen Yourish. 2016. "\$2 Billion Worth of Free Media for Donald Trump." New York Times, March 15.

Dowdle, Andrew J., Randall E. Adkins, and Wayne P. Steger. 2009. "The Viability Primary: Modeling Candidate Support before the Primaries." Political Research Quarterly 62(1): 77-91.

Druckman, James N. and Arthur Lupia. 2000. "Preference Formation." Annual Review of Political Science 3: 1-24.

Farnsworth, Stephen J. and Robert S. Lichter. 2010. The Nightly News Nightmare: Media Coverage of US Presidential Elections, 1988-2008. Lanham, MD: Rowman \& Littlefield Publishers.

Francia, Peter L. 2017. "Free Media and Twitter in the 2016 Presidential Election: The Unconventional Campaign of Donald Trump." Social Science Computer Review 36(4): 440-55. 
Google. 2016. “Google Trends.” Available at https:// www.google.com/trends/.

Graber, Doris A. and James M. Smith. 2005. "Political Communication Faces the 21st Century." Journal of Communication 55(3): 479-507.

Hackett, Robert A. 1984. "Decline of a Paradigm? Bia$s$ and Objectivity in News Media Studies." Critical Studies in Media Communication 1(3): 229-59.

Hadley, Arthur T. 1976. The Invisible Primary. Upper Saddle River, NJ: Prentice-Hall.

Hamilton, James. 2004. All the News That's Fit to Sell: How the Market Transforms Information into News. Princeton, NJ: Princeton University Press.

Han, Lori Cox. 2011. "Off to the (Horse) Races: Media Coverage of the "Not-So-Invisble" Invisible Primary of 2007." In From Votes to Victory: Winning and Governing the White House in the Twenty-First Century, ed. Meena Bose. College Station: Texas A\&M University Press.

Haynes, Audrey. 2008. "Media and Presidential Nomination Campaigns: When Bad News Becomes Good News (or at Least a Little Better)." American Review of Politics 28: 343-59.

Huffington Post. 2016. "HuffPost Pollster." Available at http://elections.huffingtonpost.com/pollster.

Internet Archive. 2015. "About the TV News Archive." Available at https://archive.org/details/tv.

Irwin, Galen A. 2002. "According to the Polls: The Influence of Opinion Polls on Expectations." Public Opinion Quarterly 66(1): 92-104.

Iyengar, Shanto, Helmut Norpoth, and Kyu S. Hahn. 2004. "Consumer Demand for Election News: The Horserace Sells." Journal of Politics 66(1): 157-75.

Kennedy, Courtney, Mark Blumenthal, Scott Clement, Joshua D. Clinton, Claire Durand, Charles Franklin, Kyley McGeeney, Lee Miringoff, Kristen Olson, Douglas Rivers, Lydia Saad, G. Evans Witt, and Christopher Wlezien. 2018. "An Evalution of the 2016 Election Polls in the United States." Public Opinion Quarterly 82(1): 1-33.

Lazarsfeld, P. F. and R. K. Merton. 1948. "Mass Communication, Popular Taste and Organized Social Action." Media Studies: A Reader. 2nd ed. Indianapolis, IN: Bobbs-Merrill Co.

Lee, Angela M., Seth C. Lewis, and Matthew Powers. 2014. "Audience Clicks and News Placement: A Study of Time-Lagged Influence in Online Journalism.” Communication Research 41(4): 505-30.

Leeper, Thomas J. and Rune Slothuus. 2014. "Political Parties, Motivated Reasoning, and Public Opinion Formation.” Political Psychology 35(1): 129-156.

Libit, Daniel. 2015. "Is John Kasich the GOP Media Darling Who Could Finally Win?” CNBC
September 14. Available at https://www.cnbc.com/ 2015/09/14/is-john-kasich-the-gop-media-darlingwho-could-finally-win.html.

McCombs, Maxwell. 2013. Setting the Agenda: The Mass Media and Public Opinion. Hoboken, NJ: John Wiley $\&$ Sons.

McManus, John H. 1994. Market-Driven Journalism: Let the Citizen Beware? Thousand Oaks, CA: Sage Publications.

Muñoz-Torres, Juan Ramón. 2012. "Truth and Objectivity in Journalism: Anatomy of an Endless Misunderstanding." Journalism Studies 13(4): 566-82.

Norrander, Barbara. 2006. "The Attrition Game: Initial Resources, Initial Contests and the Exit of Candidates during the US Presidential Primary Season." British Journal of Political Science 36(3): 487-507.

Patterson, Thomas E. 1980. The Mass Media Election: How Americans Choose Their President. Westport, CT: Praeger. 2005. "Of Polls, Mountains: US Journalists and

Their Use of Election Surveys." Public Opinion Quarterly 69(5): 716-24.

- 2013. Informing the News: The Need for KnowledgeBased Journalism. New York: Vintage Books.

- 2016. "Pre-Primary News Coverage of the 2016 Presidential Race: Trump's Rise, Sanders' Emergence, and Clinton's Struggle." Harvard Kennedy School, Shorenstein Center on Media, Politics and Public Policy. June 13.

Ripberger, Joseph T. 2011. "Capturing Curiosity: Using Internet Search Trends to Measure Public Attentiveness." Policy Studies Journal 39(2): 239-59.

Robinson, Michael J. and Margaret A. Sheehan. 1983. Over the Wire and on TV: CBS and UPI in Campaign'80. New York: Russell Sage Foundation.

Rothschild, David and Neil Malhotra. 2014. "Are public Opinion Polls Self-Fulfilling Prophecies?” Research \& Politics 1(2): 1-10.

Shoemaker, Pamela J. and Tim P. Vos. 2009. Gatekeeping Theory. Abingdon, UK: Routledge.

Sides, John. 2015. "Why Is Trump Surging? Blame the Media." Washington Post, July 20. Available at https:// www.washingtonpost.com/news/monkey-cage/wp/ 2015/07/20/why-is-trump-surging-blame-the-media/? utm_term=.7868c4ac4bc6.

Sides, John and Lynn Vavreck. 2013. The Gamble: Choice and Chance in the 2012 Presidential Election. Princeton, NJ: Princeton University Press.

Silver, Nate. 2015. "Trump Boom or Trump Bubble?" Five Thirty Eight. Available at http://fivethirtyeight. com/features/trump-boom-or-trump-bubble/.

Sims, Christopher A. and Zha. Tao 1999. "Error Bands for Impulse Responses." Econometrica 67(5): 1113-56.

Skewes, Elizabeth A. and Patrick Lee Plaisance. 2005. "Who's News? A New Model for Media Coverage of Campaigns." Journal of Mass Media Ethics 20(2-3): 139-58. 
Soroka, Stuart N. 2003. "Media, Public Opinion, and Foreign Policy." Harvard International Journal of Press/ Politics 8(1): 27-48.

Steger, Wayne. 2000. "Do Primary Voters Draw from a Stacked Deck? Presidential Nominations in an Era of Candidate-Centered Campaigns." Presidential Studies Quarterly 30(4): 727-53.

. 2013. "Polls and Elections: Two Paradigms of Presidential Nominations." Presidential Studies Quarterly 43(2): 377-87.

Tan, Yue and David H. Weaver. 2007. "Agenda-Setting Effects among the Media, the Public, and Congress, 1946-2004." Journalism \& Mass Communication Quarterly 84(4): 729-44.

Tandoc, Edson C. Jr. 2014. "Journalism Is Twerking? How Web Analytics Is Changing the Process of Gatekeeping." New Media \& Society 16(4): 559-75.
Van Aelst, Peter and Stefaan Walgrave. 2011. "Minimal or Massive? The Political Agenda-setting Power of the Mass Media According to Different Methods." International Journal of Press/Politics 16(3): 295-313.

Welbers, Kasper, Wouter Van Atteveldt, Jan Kleinnijenhuis, Nel Ruigrok, and Joep Schaper. 2016. "News Selection Criteria in the Digital Age: Professional Norms Versus Online Audience Metrics." Journalism 17(8): 1037-53.

Zaller, John. 1992. The Nature and Origins of Mass Opinion. New York: Cambridge University Press.

Zhu, Jonathan J. H., Xiaohua Wang, Jie Qin, and Lingfei Wu. 2012. "Assessing Public Opinion Trends based on User Search Queries: Validity, Reliability, and Practicality." Presented at the Annual Conference of the World Association for Public Opinion Research, Hong Kong, June 14-16. 